\title{
Extreme events driving year-to-year differences in gross primary productivity across the US
}

\author{
Alexander J. Turner ${ }^{1}$, Philipp Köhler ${ }^{2}$, Troy S. Magney ${ }^{3}$, Christian Frankenberg ${ }^{2,4}$, Inez Fung ${ }^{5}$, and \\ Ronald C. Cohen ${ }^{5,6}$ \\ ${ }^{1}$ Department of Atmospheric Sciences, University of Washington, Seattle, WA, 98195, USA \\ ${ }^{2}$ Division of Geological and Planetary Sciences, California Institute of Technology, Pasadena, CA, 91226, USA. \\ ${ }^{3}$ Department of Plant Sciences, University of California, Davis, CA, 95616, USA. \\ ${ }^{4}$ Jet Propulsion Laboratory, California Institute of Technology, Pasadena, CA, 91109, USA. \\ ${ }^{5}$ Department of Earth and Planetary Sciences, University of California, Berkeley, CA, 94720, USA. \\ ${ }^{6}$ College of Chemistry, University of California, Berkeley, CA, 94720, USA.
}

Correspondence: Alexander J. Turner (turneraj@uw.edu)

\begin{abstract}
Solar-Induced chlorophyll Fluorescence (SIF) has previously been shown to strongly correlate with gross primary productivity (GPP), however this relationship has not yet been quantified for the recently launched TROPOspheric Monitoring Instrument (TROPOMI). Here we use a Gaussian mixture model to develop a parsimonious relationship between SIF from TROPOMI and GPP from flux towers across the conterminous United States (CONUS). The mixture model indicates the SIF-GPP relationship can be characterized by a linear model with two terms. We then estimate GPP across CONUS at 500-m spatial resolution over a 16-day moving window. We find that CONUS GPP varies by less than $4 \%$ between 2018 and 2019. However, we observe four extreme precipitation events that induce regional GPP anomalies: drought in west Texas, flooding in the midwestern US, drought in South Dakota, and drought in California. Taken together, these events account for $28 \%$ of the year-to-year GPP differences across CONUS.
\end{abstract}

\section{Introduction}

Terrestrial gross primary productivity (GPP) is the total amount of carbon dioxide $\left(\mathrm{CO}_{2}\right)$ assimilated by plants through photosynthesis and represents one of the main drivers of interannual variability in the global carbon cycle Le Quéré et al. (2018). As such, quantifying the spatiotemporal patterns of terrestrial GPP is critical to understanding how the carbon cycle will both respond to and influence climate. Work over the past decade has shown satellite measurements of solar-induced chlorophyll fluorescence (SIF) to correlate strongly with tower-based estimates of GPP (e.g., Frankenberg et al., 2011; Yang et al., 2015; Sun et al., 2017; Turner et al., 2020; Wang et al., 2020) and are often used as a remote-sensing proxy for GPP.

This relationship between SIF and GPP is typically expressed through a pair of light use efficiency models Monteith (1972) that relate GPP and SIF to the absorbed photosynthetically active radiation (APAR):

$\mathrm{GPP}=\mathrm{APAR} \times \Phi_{\mathrm{CO}_{2}}$

$\mathrm{SIF}=\operatorname{APAR} \times \beta \Phi_{\mathrm{F}}$ 
https://doi.org/10.5194/bg-2021-49

Preprint. Discussion started: 5 March 2021

(c) Author(s) 2021. CC BY 4.0 License.

\section{(c) (i)}

where $\Phi_{\mathrm{CO}_{2}}$ is the light use efficiency of $\mathrm{CO}_{2}$ assimilation, $\Phi_{\mathrm{F}}$ is the fluorescence yield, and $\beta$ is the probability of fluoresced photons escaping the canopy. Solving for APAR and substituting, we can rewrite GPP as:

$\mathrm{GPP}=\frac{\Phi_{\mathrm{CO}_{2}}}{\beta \Phi_{\mathrm{F}}} \mathrm{SIF}$

The derivation follows from Lee et al. (2013), Guanter et al. (2014), Sun et al. (2017), and others.

This seemingly straightforward relationship between SIF and GPP has been widely used to infer GPP from measurements of SIF (e.g., Frankenberg et al., 2011; Parazoo et al., 2014; Yang et al., 2015, 2017; Sun et al., 2017, 2018; Magney et al., 2019; Turner et al., 2020) with some work showing that SIF captures more variability in GPP than APAR alone (e.g., Yang et al., 2015, 2017; Magney et al., 2019). However, there is much complexity encapsulated in the first term of Eq. $3\left(\Phi_{\mathrm{CO}_{2}} / \beta \Phi_{\mathrm{F}}\right)$. There is an ongoing debate about what exactly SIF is telling us about GPP (e.g., Joiner and Yoshida, 2020; Maguire et al., 2020; Dechant et al., 2020; He et al., 2020; Marrs et al., 2020) and the spatio-temporal scales at which SIF and GPP correlate well. A recent paper from Magney et al. (2020) presents a concise summary of the covariation between SIF and GPP at different spatiotemporal scales and how non-linear relationships at the leaf-scale often integrate to a linear response at the canopy-scale. This is due, in large part, to the fact that most of our satellite measurements occur near the middle of the day when the $\Phi_{\mathrm{CO}_{2}}-\Phi_{\mathrm{F}}$ response is more-or-less linear and the observed signal is integrated over many leaves.

Here we focus on the ecosystem-scale relationship between SIF and GPP, as that is the relevant observable scale from spaceborne instruments. We begin by characterizing the relationship between instantaneous SIF from TROPOMI and half-hourly GPP from flux towers. Following this, we use this ecosystem-scale relationship to infer GPP at a spatial resolution of 500-m using TROPOMI SIF measurements and identify drivers of interannual variability in GPP. Previous work has identified effects such as seasonal redistribution Butterfield et al. (2020), drought (e.g., Sun et al., 2015), and flooding Yin et al. (2020) as important drivers of interannual variability in GPP.

\section{Identifying distinct relationships between SIF and GPP}

We build on our previous work Turner et al. (2020) downscaling measurements of SIF to 500-m spatial resolution. Briefly, the TROPOspheric Monitoring Instrument (TROPOMI; Veefkind et al., 2012) is a nadir-viewing imaging spectrometer. TROPOMI has a 2,600 km swath with a nadir spatial resolution of $5.6 \mathrm{~km}$ along track and $3.5 \mathrm{~km}$ across track. Köhler et al. (2018) presented the first retrievals of SIF from TROPOMI. As in Turner et al. (2020), we apply a post hoc bias correction to ensure positivity of monthly average values as systematically negative SIF values are non-physical. We downscale individual TROPOMI scenes using the near-infrared reflectance of vegetation index $\left(\mathrm{NIR}_{\mathrm{v}}\right)$ that was proposed by Badgley et al. (2017, 2019). We use

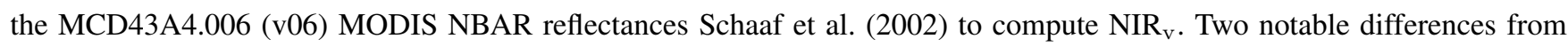
Turner et al. (2020) are: 1) the analysis is extended to cover all of CONUS and 2) we now use a 16-day moving window, thus including a full orbit cycle in each averaging window to minimize effects due to viewing-illumination geometry and noise. Supplemental Fig. S3 shows the improvement when averaging to longer temporal windows with an $r$ of $0.66,0.74,0.79$, and 0.82 for instantaneous, 8-day, 16-day, and 32-day temporal windows, respectively. 


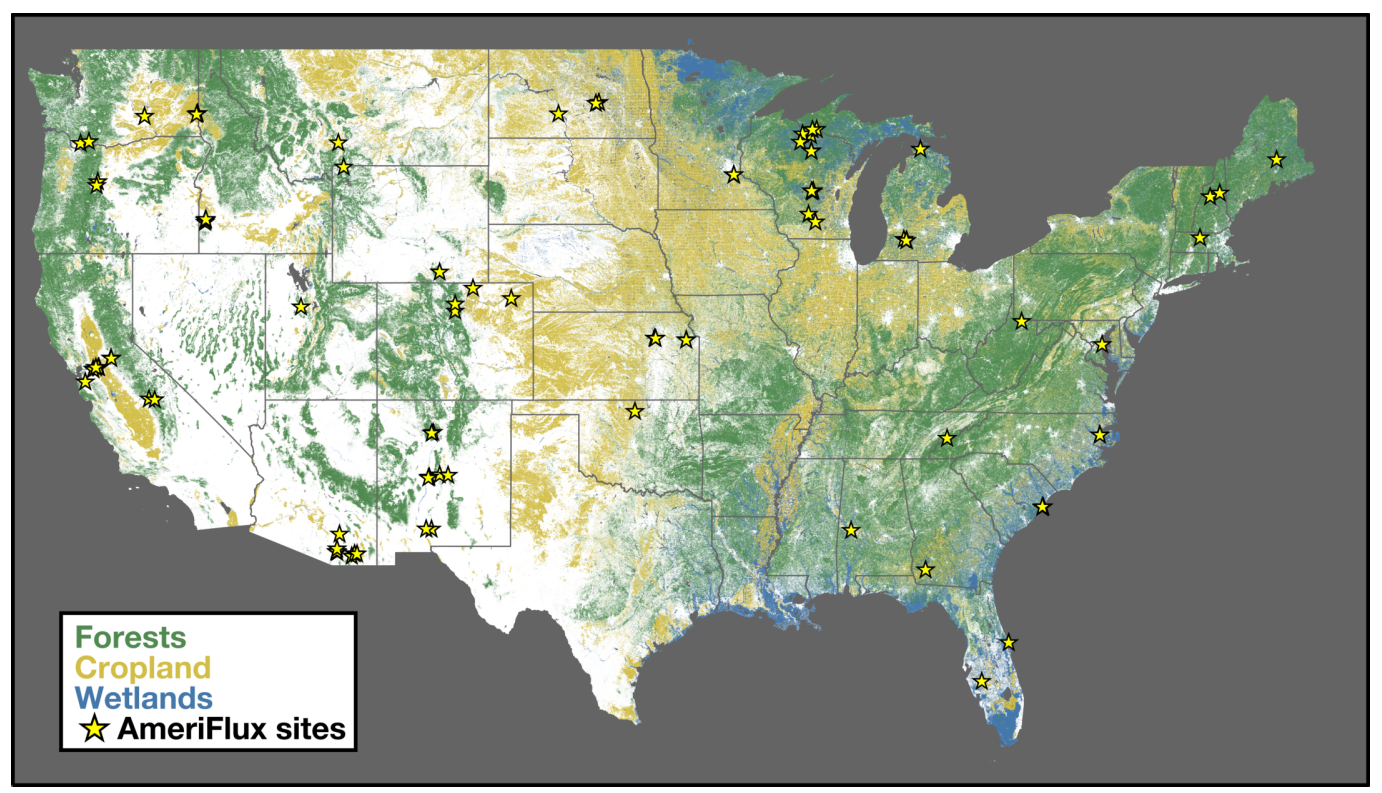

Figure 1. Dominant landcover over conterminous United States (CONUS). Colors show the dominant landcover over CONUS. Classification is based on the 2019 USDA CropScape database USDA (2018). Forests are shown in green croplands in yellow, and wetlands in blue. Location of 82 AmeriFlux sites used in this study are shown as yellow stars.

The extension to CONUS facilitates comparison of TROPOMI SIF retrievals to flux tower data over a more representative set of ecosystems and robustly infer the SIF-GPP relationship. Specifically, there are 82 AmeriFlux sites Baldocchi et al. (2001) within CONUS that reported data in 2018, 2019, or 2020 whereas Turner et al. (2020) only included 11 sites and did not have data from forests. Figure 1 shows the location of these 82 AmeriFlux sites overlaid on the dominant landcover. These eddy covariance sites provide a direct measure of net ecosystem exchange (NEE; $\mathrm{CO}_{2}$ fluxes) Baldocchi et al. (1988). We use GPP that has been partitioned by the group operating the site. If GPP is not provided we compute it using nighttime measurements of NEE as a proxy for ecosystem respiration Reichstein et al. (2005). The AmeriFlux sites used here cover 10 ecosystems as defined by the International Geosphere-Biosphere Programme: evergreen needleleaf forest, deciduous broadleaf forest, mixed forest, grassland, cropland, wetland, woody savanna, savanna, open shrubland, and closed shrubland.

We characterize the relationship between TROPOMI SIF and AmeriFlux GPP by plotting downscaled instantaneous SIF observations against the nearest AmeriFlux GPP data in time (see Supplemental Figs. S1-S3). Specifically, the 6 steps we take here are: 1) apply the post hoc bias correction to the TROPOMI SIF data, 2) find all TROPOMI scenes that cover an AmeriFlux site, 3) downscale TROPOMI scenes to 500-m using MODIS NIR ${ }_{\mathrm{v}}$, 4) construct a timeseries of SIF observations from the 500-m grid cell that contains the AmeriFlux site, 5) construct a timeseries of AmeriFlux GPP data that are coincident in time with the TROPOMI overpass, and 6) regress SIF on GPP with a bisquare regression. The bisquare regression was chosen due to robustness against outliers. Additionally, we force the regression through the origin based on the physical constraint that GPP should be zero if SIF is zero. We observe a linear relationship between SIF and GPP when plotted against 
https://doi.org/10.5194/bg-2021-49

Preprint. Discussion started: 5 March 2021

(c) Author(s) 2021. CC BY 4.0 License.

all ecosystems (Supplemental Figure S1) and when separated by ecosystem (Supplemental Figure S2). Notable exceptions are closed shrubland, open shrubland, and savanna ecosystems where SIF explains less than $10 \%$ of the variability in GPP for AmeriFlux sites in those ecosystems due, in part, to a low signal-to-noise ratio. These ecosystems typically have a small signal and the bright surfaces often result in a higher retrieval uncertainty. This combination of a small signal and high retrieval uncertainty results in a low signal-to-noise ratio, complicating efforts to derive a robust relationship between SIF and GPP for these ecosystems.

Many of the ecosystems exhibit a similar linear relationship between SIF and GPP, which begs the question: "what ecosystems have a distinct SIF-GPP relationship?" To address this, we bootstrap the bisquare regression for each ecosystem 2000 times. The slopes from this bootstrap can be seen in Figure 2. The range of slopes vary from 13 to $18\left(\mu \mathrm{molm}^{-2} \mathrm{~s}^{-1}\right) /\left(\mathrm{mW} \mathrm{m}^{-2} \mathrm{sr}^{-1} \mathrm{~s}^{-1}\right)$ with grasslands at the low end and evergreen needleleaf forests at the high end. We then use a two component Gaussian mixture model (see, for example, Bishop, 2007) to identify clusters of ecosystems with a similar SIF-GPP relationship. The implementation of our Gaussian mixture model is adapted from Turner and Jacob (2015). Parameters of the mixture model are obtained via an iterative expectation-maximization algorithm. A drawback of these mixture models is they often find local minima. To address this, we repeat the fitting of the mixture model with multiple initializations and use simulated annealing to search for a global minimum. We tested a range of mixture model sizes and found a mixture of two Gaussians to be the most robust. The resulting mixture model is overlaid on the histogram in Figure 2.

We observe a clustering of ecosystems with SIF-GPP relationships around $16.4\left(\mu \mathrm{molm}^{-2} \mathrm{~s}^{-1}\right) /\left(\mathrm{mW} \mathrm{m}^{-2} \mathrm{sr}^{-1} \mathrm{~s}^{-1}\right)$. This grouping is the dominant weighting term for wetlands, evergreen needleleaf forest, deciduous broadleaf forest, mixed forest, cropland, and woody savanna. We refer to this cluster as the "Dominant Cluster" and assume that ecosystems not specifically mentioned elsewhere will have a response that is similar to this primary cluster. The other component of the mixture model corresponds to grasslands. Ecosystems not explicitly mentioned use the "Dominant Cluster" for scaling SIF to GPP. Table 1 lists the SIF-GPP relationships for these two clusters. Previous work has also found unique SIF-GPP relationships between C3 and C4 plants using measurements from a tower including a non-linear response in C3 plants He et al. (2020), we examined this here using two AmeriFlux sites in corn fields and two in potato fields. We do observe potential differences in the SIF-GPP relationship between these C3 and C4 systems (see Supplemental Figure S5). The difference in SIF-GPP relationship for C3 and C4 systems seen here is also similar to what was observed using NIR ${ }_{\mathrm{v}}$ Badgley et al. (2019). These relationships can be used to reconstruct GPP from TROPOMI SIF as: GPP $=\mathrm{SIF} \times\left(\sum_{i} f_{i} s_{i}\right)$ where $s_{i}$ is the SIF-GPP relationship in Table 1 for the $i^{\text {th }}$ cluster and $f_{i}$ is the fraction of a grid cell represented by that cluster.

TROPOMI is in low earth orbit and only observes a snapshot in time. The equatorial overpass time at nadir is 13:30 local time. By assuming that GPP scales linearly with PAR (i.e., Eq. 1) we can compute a correction factor to estimate daily integrated GPP. More formally, we scale the instantaneous SIF by the ratio of the integral of the cosine of the solar zenith angle (SZA) over the day to $\cos$ (SZA) from the TROPOMI overpass time. Putting everything together, we estimate daily GPP from TROPOMI SIF observations as:

$\operatorname{GPP}(x, y, t)=\operatorname{SIF}(x, y, t) \cdot \gamma \sum_{i} s_{i} f_{i}(x, y) \cdot \frac{\int_{\tau_{0}}^{\tau_{f}} \cos [\mathrm{SZA}(x, y, \tau)] \mathrm{d} \tau}{\cos \left[\operatorname{SZA}\left(x, y, \tau_{s}\right)\right]}$ 


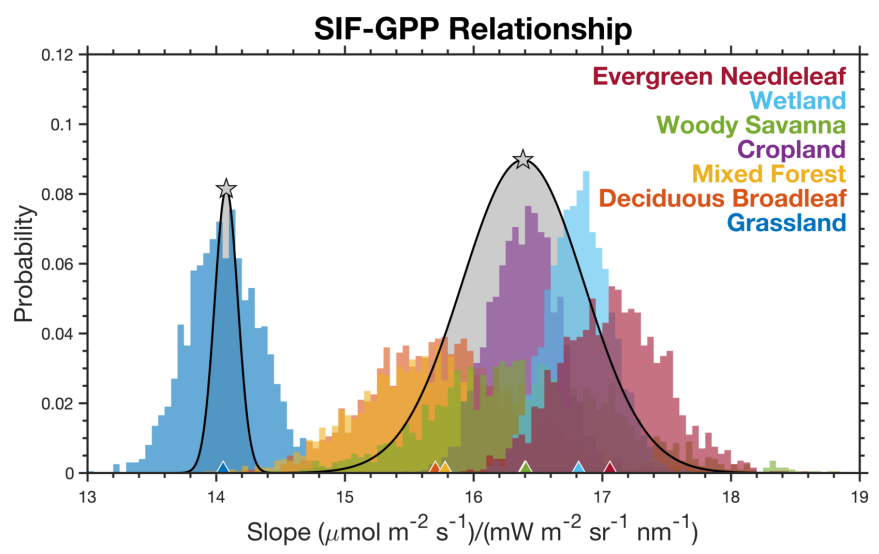

Figure 2. Identifying distinct SIF-GPP relationships across ecosystems. Histogram shows the distribution of slopes that map SIF to GPP using a bisquare regression and a 2000 member bootstrap. Colors denote the different ecosystems and triangles at the bottom show the mean for that ecosystem. Gray distributions are from a two-member Gaussian Mixture Model and the stars indicate the mean for that component.

Table 1. SIF-GPP relationships for different groupings.

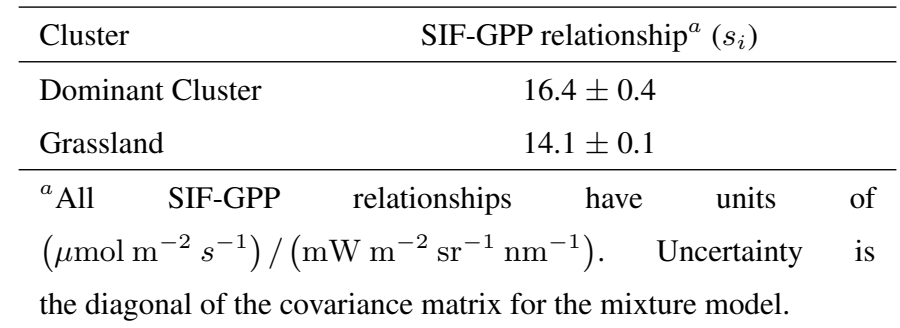

1 where $\operatorname{SIF}(x, y, t)$ is the 500-m downscaled SIF using a 16-day moving window, $\gamma$ is a unit conversion from $\mu$ mol to gC, $s_{i}$ is 2 the SIF-GPP relationship inferred from comparison with AmeriFlux GPP (see Table 1), $f_{i}(x, y)$ is the fraction of the grid cell 3 represented by the $i^{\text {th }}$ cluster, SZA is the local solar zenith angle, $\tau_{0}$ is sunrise, $\tau_{f}$ is sunset, and $\tau_{s}$ is the hour corresponding to 4 the TROPOMI overpass time. We do not include information on cloud cover in our approach, this could potentially be included 5 in the future to account for diurnal variations in PAR.

\section{Drivers of interannual variations in US gross primary productivity}

7 Figure 3 shows annual mean GPP across CONUS inferred from TROPOMI SIF measurements using Eq. 4. A number of 8 prominent features are visible such as the Central Valley of California, the Snake River Valley in Idaho, and the Adirondack

9 Mountains in upstate New York. California's Central Valley and Idaho's Snake River Valley are both major agricultural regions in the western US (e.g., the Central Valley of Califoria accounts for more than $15 \%$ of irrigated land in the US). The Adirondack 
https://doi.org/10.5194/bg-2021-49

Preprint. Discussion started: 5 March 2021

(C) Author(s) 2021. CC BY 4.0 License.

1 Mountains are a roughly circular dome that rise above the surrounding lowlands, resulting in a shorter growing season and lower

2 annual mean GPP. This shortened growing season can be seen in an animation of GPP over CONUS (Supplemental Movie S1).

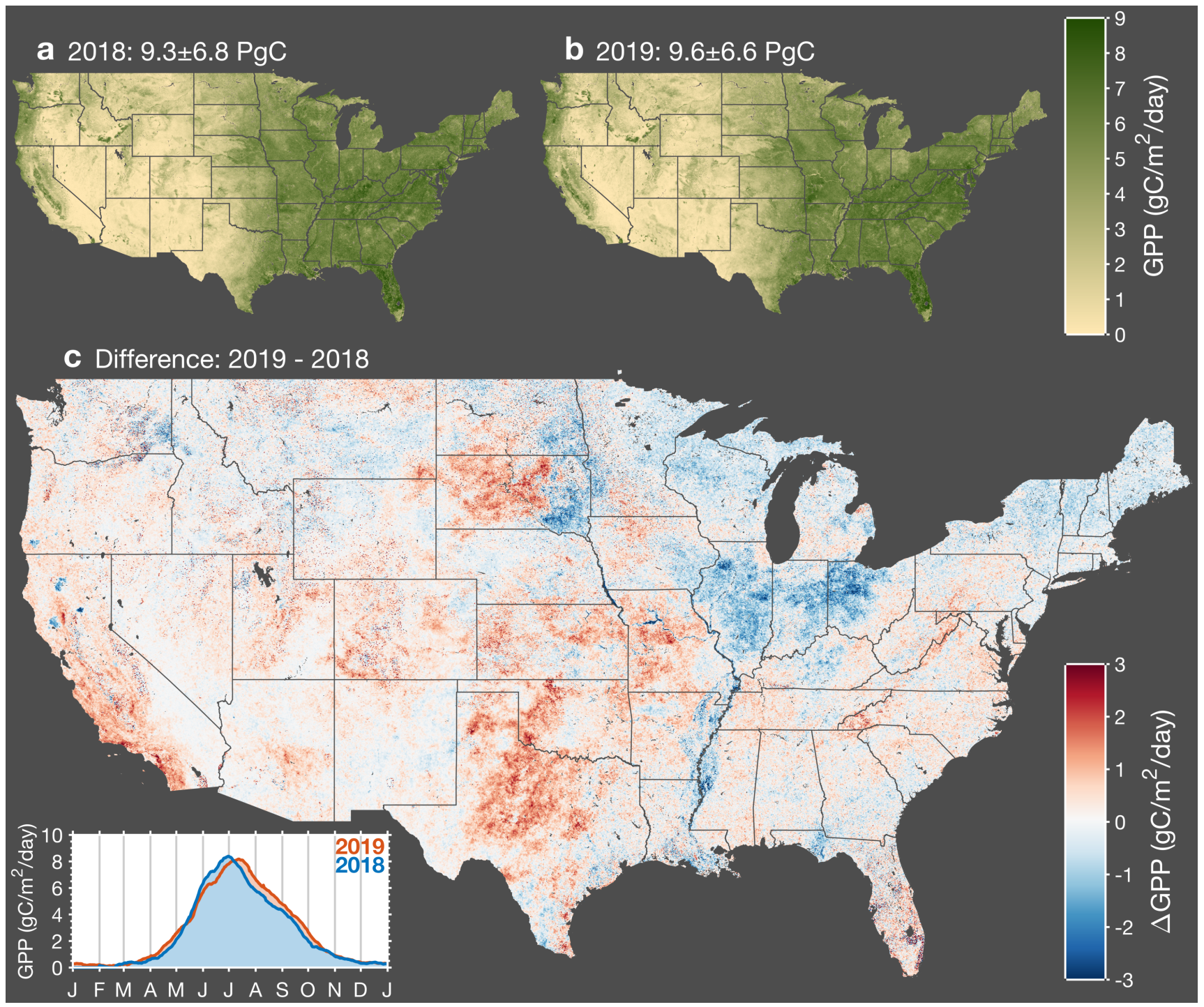

Figure 3. Interannual variations in gross primary productivity across CONUS. Map of annual mean GPP for 2018 (panel a) and 2019 (panel b). (Panel c) Map of the difference in annual mean GPP between 2019 and 2018. Red indicates higher GPP in 2019 and red indicates higher GPP in 2018. Inset in bottom left corner shows a timeseries of the average GPP across CONUS for 2018 and 2019.

3 We observe substantial GPP across the eastern US (delineated here by $98^{\circ} \mathrm{W}$ ) with annual mean values generally in excess of $45 \mathrm{gC} / \mathrm{m}^{2} /$ day. This region accounts for less than half of the land but more than $70 \%$ of the annual GPP. This delineation in GPP

5 roughly coincides with the location of drylands in CONUS that are more sensitive to changes in precipitation; drylands are also 
https://doi.org/10.5194/bg-2021-49

Preprint. Discussion started: 5 March 2021

(c) Author(s) 2021. CC BY 4.0 License.

\section{(c) (i)}

projected to expand in future climate Yao et al. (2020). Most of the large year-to-year differences occur in these western US drylands (see Fig. 3c), a notable exception being a negative GPP anomaly in 2019 relative to 2018 that extended across Illinois, Indiana, and Ohio. Here we highlight four precipitation-driven GPP anomalies, which taken together, account for $28 \%$ of the interannual GPP variability across the United States: 1) 2018 drought in west Texas, 2) 2019 midwestern crop flooding, 3) 2018 drought in South Dakota, and 4) 2018 drought in California. Figure 4 summarizes the interannual precipitation differences that we hypothesize are responsible for explaining these four GPP anomalies.

The largest positive GPP anomaly in 2019 relative to 2018 was observed across western Texas. This single event accounted for $11 \%$ of the year-to-year difference in GPP across CONUS with an annual GPP of $0.65 \pm 0.47 \mathrm{PgC}$ in 2018 and $0.76 \pm$ $0.45 \mathrm{PgC}$ in 2019. From Figure 4a, we observe 50\% higher GPP in spring 2019 compared to spring 2018. This increase in GPP was driven by a lack of precipitation in spring 2018. The cumulative precipitation from October 2017 through June 2018 was 50\% less than October 2018 through June $2019(500 \mathrm{~mm}$ vs $1000 \mathrm{~mm})$. The other notable difference between GPP in 2018 and 2019 was a second peak during fall 2018 that was not present in 2019. This second peak coincided with a series of precipitation events beginning in early September. This tight coupling between GPP and precipitation is expected for dryland systems such as west Texas (e.g., Smith et al., 2019). The seasonal GPP dynamics inferred from TROPOMI SIF are also present in the MODIS vegetation index $\mathrm{NIR}_{\mathrm{v}}$, albeit with slight differences in magnitude, implying convergent responses in SIF and NIR for this ecosystem.

The second largest anomaly is the reduction in 2019 GPP relative to 2018 across midwestern crop areas (specifically Illinois, Indiana, and Ohio) that accounted for 7\% of the year-to-year difference in CONUS GPP. The 2018 annual GPP was $0.70 \pm$ $0.12 \mathrm{PgC}$ and $0.63 \pm 0.14 \mathrm{PgC}$ in 2019. We observe a decrease in the maximum GPP between 2019 and 2018 as well as a two week delay in the timing of the maximum. This anomaly was highlighted in recent work from Yin et al. (2020) who attribute the anomaly to flooding in the midwestern US. The flooding delayed planting of crops by two weeks and resulted in decreased carbon uptake across the midwestern crop areas and Mississippi Alluvial Valley, where we also observe a negative anomaly in Figure 3c. Yin et al. (2020) provide a detailed discussion of these floods and their impacts on crop productivity.

South Dakota exhibits a dipole with positive anomalies in 2019 in the west and negative anomalies in the east, again relative to 2018. The 2018 annual GPP was $0.20 \pm 0.09 \mathrm{PgC}$ and $0.63 \pm 0.08 \mathrm{PgC}$ in 2019. The negative anomalies in the east are driven by the flooding events discussed above and in Yin et al. (2020). However, the positive anomaly in western portion of the state is the dominant term. This positive anomaly is driven by a series of summer precipitation events that served to extend the growing season across the western plains. From Figure 4c, we can see three precipitation events throughout the mid-to-late summer that coincide with pauses in senesence: mid-July, early August, and mid-September. As with Texas, this highlights the tight coupling between GPP and precipitation for dryland systems. In toto, these precipitation events served to increase statewide GPP in 2019 relative to 2018.

The final notable anomaly is California's positive GPP anomaly in 2019. The 2018 annual GPP was $0.27 \pm 0.24 \mathrm{PgC}$ and $0.33 \pm 0.26 \mathrm{PgC}$ in 2019. 2018 was a mild drought in California with $\sim 80 \%$ of the state being classified as abnormally dry; 2019 had 50\% more precipitation during the water year than 2018 (Figure 4c). Two consequences of this drought in 2018 were: a delayed onset of photosynthesis and a mid-summer senescence. The onset of photosynthesis in 2018 coincided with a series 


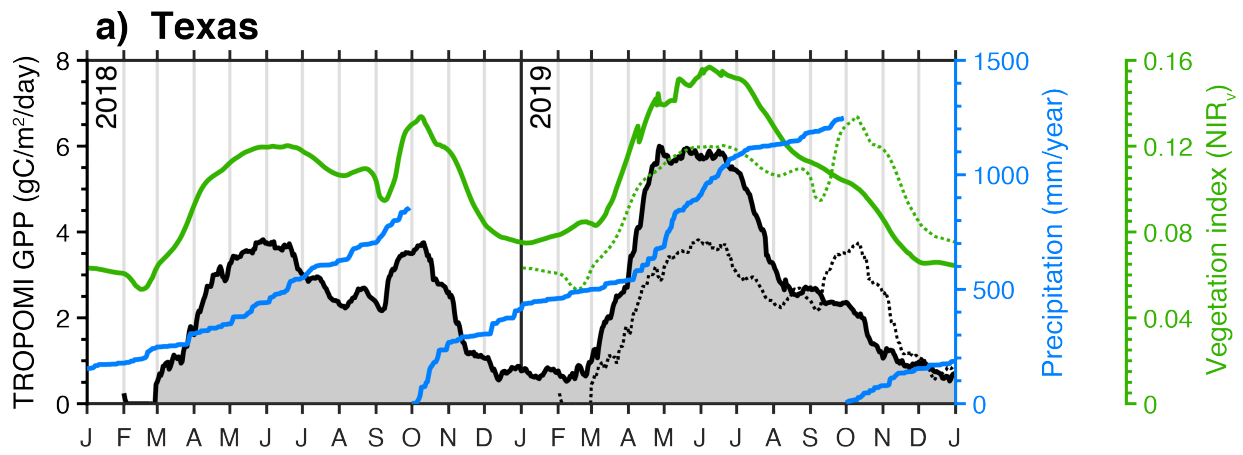

b) Midwest Crop Areas: Illinois, Indiana, \& Ohio

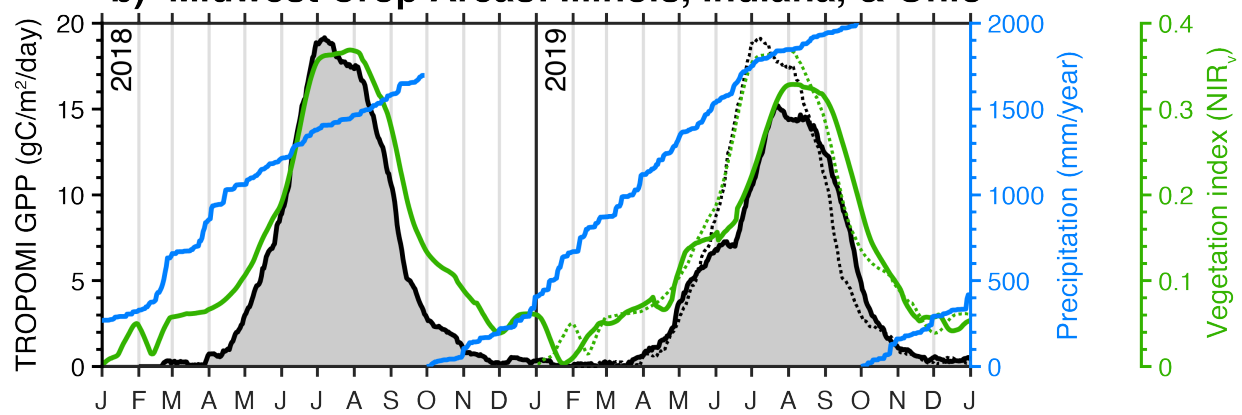

c) South Dakota

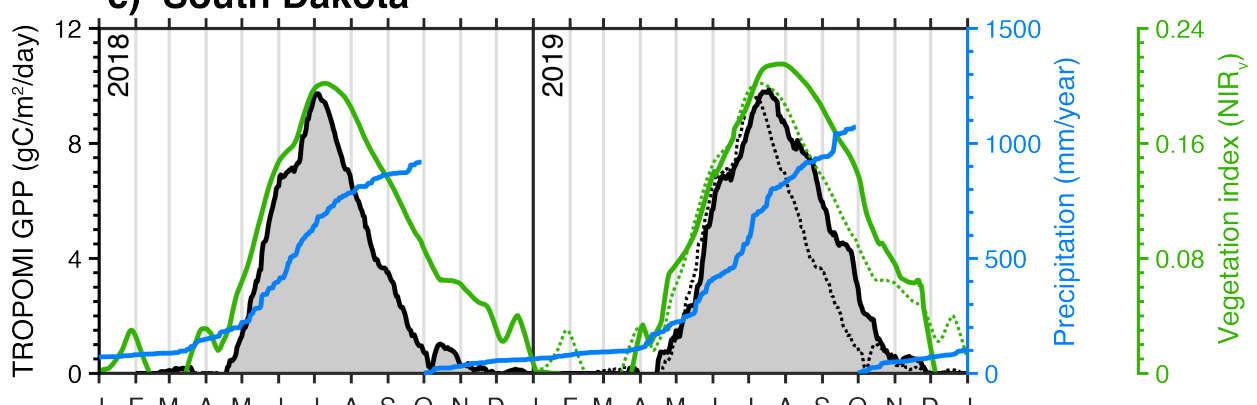

d) California

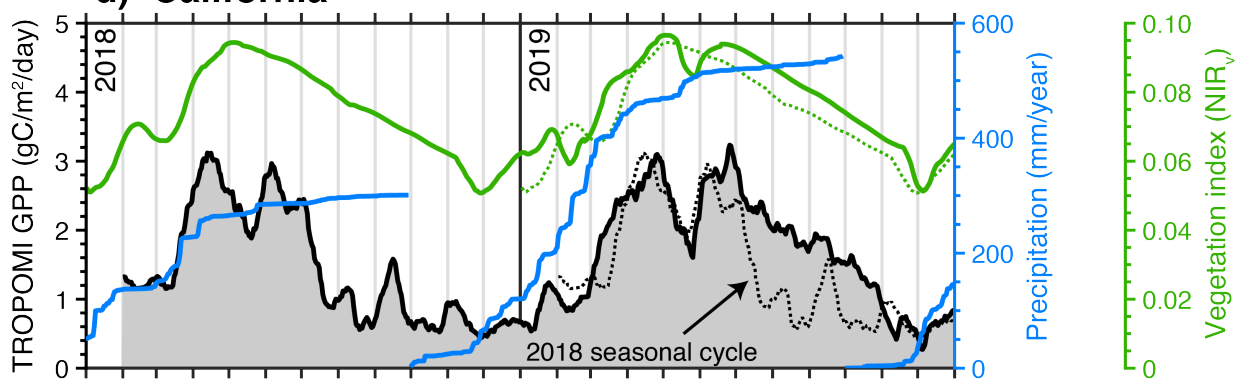

Figure 4. Major drivers of interannual variability in CONUS GPP. Black line shows the TROPOMI-derived GPP over Texas (a), the midwest crop region (b), South Dakota (c), and California (d). Blue line shows the cumulative precipitation over the water year as measured

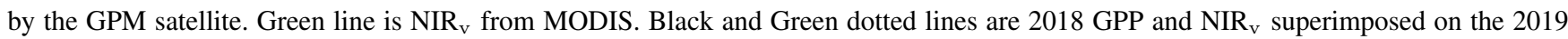
timeseries. 
https://doi.org/10.5194/bg-2021-49

Preprint. Discussion started: 5 March 2021

(c) Author(s) 2021. CC BY 4.0 License.

\section{(c) (i)}

of atmospheric rivers that delivered about a third of the total precipitation that year, indicating a water limitation up to that point. In contrast, 2019 had ample precipitation through the winter and we observe both an earlier onset of photosynthesis and an extension of the growing season into the fall. Evergreen forests are the main contributor to the SIF signal during the summer and fall Turner et al. (2020) and, as such, will be more sensitive to the accumulated precipitation. The spatial pattern of the differences in August-November GPP (Fig. S4) strongly correlate with evergreen forests.

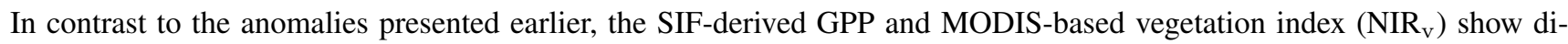
vergent seasonal dynamics for California. $\mathrm{NIR}_{\mathrm{v}}$ shows small differences between 2018 and 2019 with a strong similarity to the 2019 SIF-derived GPP. The seasonality of NIR $_{\mathrm{v}}$ is similar to that of the leaf area index (LAI) derived from MODIS (see Supplemental Figure 6), implying a biophysical signal. Vegetation indices estimate photosynthetic capacity provided optimal soil moisture, temperature, and PAR are known Sellers (1985). As such, this suggests that we observed a down-regulation of photosynthesis from evergreen forests in response to a water limitation during fall 2018, whereas these forests were close to photosynthetic capacity in fall 2019 resulting in a similar seasonality to 2018 and 2019 NIR $_{\mathrm{v}}$. Sims et al. (2014) also report a low sensitivity of MODIS vegetation indices to drought stress in forests.

\section{Conclusions}

We have developed a parsimonious relationship between measurements of SIF from TROPOMI and GPP inferred from flux towers. This relationship allows for estimation of GPP directly from TROPOMI SIF measurements. We combine this SIFGPP relationship with work downscaling TROPOMI data to 500-m spatial resolution to construct estimates of GPP across the conterminous United States in 2018 and 2019. Our estimate of US GPP varies by less than 4\% between 2018 and 2019. We do, however, observe large regional anomalies that are driven by extreme precipitation events. Namely, west Texas, South Dakota, and California experienced droughts in 2018 while midwestern US crop areas (Illinois, Indiana, and Ohio) experienced flooding in 2019. Taken together, these four events account for $28 \%$ of the year-to-year variability in GPP across the conterminous United States.

The impact of the west Texas drought, South Dakota drought, and midwestern flooding are observed in other remotesensing measures of photosynthetic capacity such as $\mathrm{NIR}_{\mathrm{v}}$ while the California drought shows a divergent result using SIF; the divergent responses are driven by specific ecosystems such as evergreen forests. Our work suggests that SIF provides a measure of photosynthetic activity as opposed to photosynthetic capacity, and converge with other remote-sensing measures under nonstressed conditions. Future work investigating the response to extreme events across ecosystems may provide additional insight into these divergent responses in remote-sensing measurements related to photosynthesis.

Acknowledgements. We are grateful to the team that has realized the TROPOMI instrument, consisting of the partnership between Airbus Defence and Space, KNMI, SRON, and TNO, commissioned by NSO and ESA. We acknowledge the following AmeriFlux sites for their data records: US-ALQ, US-ARM, US-Bi1, US-Bi2, US-CF1, US-CF2, US-CF3, US-CF4, US-CS1, US-CS2, US-CS3, US-EDN, US-GLE, 
https://doi.org/10.5194/bg-2021-49

Preprint. Discussion started: 5 March 2021

(c) Author(s) 2021. CC BY 4.0 License.

(c) (1)

US-Hn2, US-Hn3, US-Ho1, US-JRn, US-Jo2, US-KS3, US-Los, US-Me2, US-Me6, US-Men, US-Mpj, US-MtB, US-Myb, US-NC2, USNC3, US-NC4, US-R1s, US-Rms, US-Ro4, US-Ro5, US-Ro6, US-Rwf, US-Rws, US-SRG, US-SRM, US-Seg, US-Ses, US-Sne, US-Snf, US-Syv, US-Ton, US-Tw1, US-Tw4, US-Tw5, US-UMd, US-Var, US-Vcm, US-Vcp, US-WCr, US-Whs, US-Wjs, US-Wkg, US-xAB, USxBR, US-xCP, US-xDC, US-xDL, US-xHA, US-xJE, US-xJR, US-xKA, US-xKZ, US-xNG, US-xNQ, US-xRM, US-xSE, US-xSL, USxSP, US-xSR, US-xST, US-xTE, US-xUK, US-xUN, US-xWD, US-xWR, US-xYE. In addition, funding for AmeriFlux data resources was provided by the U.S. Department of Energy's Office of Science. Funding: AJT was supported as a Miller Fellow with the Miller Institute for Basic Research in Science at UC Berkeley. This research was funded by grants from the Koret Foundation and NASA 80NSSC19K0945 for support of the computational resources. Part of this research was funded by the NASA Carbon Cycle Science program (grant NNX17AE14G). TROPOMI SIF data generation by PK and CF is funded by the Earth Science U.S. Participating Investigator program (grant NNX15AH95G). This research used the Savio computational cluster resource provided by the Berkeley Research Computing program at the University of California, Berkeley (supported by the UC Berkeley Chancellor, Vice Chancellor for Research, and Chief Information Officer). Author contributions: AJT wrote the text with feedback from all authors. PK and CF performed the TROPOMI SIF retrievals. AJT downscaled the SIF data, conducted the AmeriFlux analysis, and drafted the figures. All authors contributed to the discussion and analysis. Competing interests: The authors declare no competing interests. Data and materials availability: Daily gridded 500-m TROPOMI SIF and GPP data from February 1, 2018 through June 15, 2020 is temporarily available on Google Drive here: "https://bit.ly/2GHEOOq", and will be uploaded to the ORNL DAAC at acceptance. 
https://doi.org/10.5194/bg-2021-49

Preprint. Discussion started: 5 March 2021

(c) Author(s) 2021. CC BY 4.0 License.

\section{References}

Badgley, G., Field, C. B., and Berry, J. A.: Canopy near-infrared reflectance and terrestrial photosynthesis, Sci Adv, 3, e1602 244, https://doi.org/10.1126/sciadv.1602244, 2017.

Badgley, G., Anderegg, L. D. L., Berry, J. A., and Field, C. B.: Terrestrial Gross Primary Production: Using NIR $V$ to Scale from Site to Globe, Global change biology, https://doi.org/10.1111/gcb.14729, 2019.

Baldocchi, D., Falge, E., Gu, L., Olson, R., Hollinger, D., Running, S., Anthoni, P., Bernhofer, C., Davis, K., Evans, R., Fuentes, J., Goldstein, A., Katul, G., Law, B., Lee, X., Malhi, Y., Meyers, T., Munger, W., Oechel, W., Paw, K. T., Pilegaard, K., Schmid, H. P., Valentini, R., Verma, S., Vesala, T., Wilson, K., and Wofsy, S.: FLUXNET: A New Tool to Study the Temporal and Spatial Variability of Ecosystem-Scale Carbon Dioxide, Water Vapor, and Energy Flux Densities, Bulletin of the American Meteorological Society, 82, 24152434, https://doi.org/10.1175/1520-0477(2001)082<2415:fantts>2.3.co;2, 2001.

Baldocchi, D. D., Hicks, B. B., and Meyers, T. P.: Measuring Biosphere-Atmosphere Exchanges of Biologically Related Gases with Micrometeorological Methods, Ecology, 69, 1331-1340, https://doi.org/10.2307/1941631, 1988.

Bishop, C. M.: Pattern Recognition and Machine Learning, Springer, 1 edn., 2007.

Butterfield, Z., Buermann, W., and Keppel-Aleks, G.: Satellite observations reveal seasonal redistribution of northern ecosystem productivity in response to interannual climate variability, Remote Sensing of Environment, 242, 111 755, https://doi.org/10.1016/j.rse.2020.111755, 2020.

Dechant, B., Ryu, Y., Badgley, G., Zeng, Y., Berry, J. A., Zhang, Y., Goulas, Y., Li, Z., Zhang, Q., Kang, M., Li, J., and Moya, I.: Canopy structure explains the relationship between photosynthesis and sun-induced chlorophyll fluorescence in crops, Remote Sensing of Environment, 241, 111 733, https://doi.org/10.1016/j.rse.2020.111733, 2020.

Frankenberg, C., Butz, A., and Toon, G. C.: Disentangling chlorophyll fluorescence from atmospheric scattering effects in $\mathrm{O}_{2} \mathrm{~A}-\mathrm{band}$ spectra of reflected sun-light, Geophysical Research Letters, 38, https://doi.org/10.1029/2010g1045896, 2011.

Guanter, L., Zhang, Y., Jung, M., Joiner, J., Voigt, M., Berry, J. A., Frankenberg, C., Huete, A. R., Zarco-Tejada, P., Lee, J. E., Moran, M. S., Ponce-Campos, G., Beer, C., Camps-Valls, G., Buchmann, N., Gianelle, D., Klumpp, K., Cescatti, A., Baker, J. M., and Griffis, T. J.: Global and time-resolved monitoring of crop photosynthesis with chlorophyll fluorescence, Proceedings of the National Academy of Sciences of the United States of America, 111, E1327-33, https://doi.org/10.1073/pnas.1320008111, 2014.

He, L., Magney, T., Dutta, D., Yin, Y., Köhler, P., Grossmann, K., Stutz, J., Dold, C., Hatfield, J., Guan, K., Peng, B., and Frankenberg, C.: From the Ground to Space: Using Solar-Induced Chlorophyll Fluorescence to Estimate Crop Productivity, Geophysical Research Letters, 47, https://doi.org/10.1029/2020g1087474, 2020.

Joiner, J. and Yoshida, Y.: Satellite-based reflectances capture large fraction of variability in global gross primary production (GPP) at weekly time scales, Agricultural and Forest Meteorology, 291, 108 092, https://doi.org/10.1016/j.agrformet.2020.108092, 2020.

Köhler, P., Frankenberg, C., Magney, T. S., Guanter, L., Joiner, J., and Landgraf, J.: Global Retrievals of Solar-Induced Chlorophyll Fluorescence With TROPOMI: First Results and Intersensor Comparison to OCO-2, Geophysical Research Letters, 45, 10,456-10,463, https://doi.org/10.1029/2018g1079031, 2018.

Le Quéré, C., Andrew, R. M., Friedlingstein, P., Sitch, S., Hauck, J., Pongratz, J., Pickers, P. A., Korsbakken, J. I., Peters, G. P., Canadell, J. G., Arneth, A., Arora, V. K., Barbero, L., Bastos, A., Bopp, L., Chevallier, F., Chini, L. P., Ciais, P., Doney, S. C., Gkritzalis, T., Goll, D. S., Harris, I., Haverd, V., Hoffman, F. M., Hoppema, M., Houghton, R. A., Hurtt, G., Ilyina, T., Jain, A. K., Johannessen, T., Jones, C. D., Kato, E., Keeling, R. F., Goldewijk, K. K., Landschützer, P., Lefévre, N., Lienert, S., Liu, Z., Lombardozzi, D., Metzl, N., Munro, 
https://doi.org/10.5194/bg-2021-49

Preprint. Discussion started: 5 March 2021

(c) Author(s) 2021. CC BY 4.0 License.

\section{(c) (i)}

D. R., Nabel, J. E. M. S., Nakaoka, S.-i., Neill, C., Olsen, A., Ono, T., Patra, P., Peregon, A., Peters, W., Peylin, P., Pfeil, B., Pierrot, D., Poulter, B., Rehder, G., Resplandy, L., Robertson, E., Rocher, M., Rödenbeck, C., Schuster, U., Schwinger, J., Séférian, R., Skjelvan, I., Steinhoff, T., Sutton, A., Tans, P. P., Tian, H., Tilbrook, B., Tubiello, F. N., van der Laan-Luijkx, I. T., van der Werf, G. R., Viovy, N., Walker, A. P., Wiltshire, A. J., Wright, R., Zaehle, S., and Zheng, B.: Global Carbon Budget 2018, Earth System Science Data, 10, 2141-2194, https://doi.org/10.5194/essd-10-2141-2018, 2018.

Lee, J. E., Frankenberg, C., van der Tol, C., Berry, J. A., Guanter, L., Boyce, C. K., Fisher, J. B., Morrow, E., Worden, J. R., Asefi, S., Badgley, G., and Saatchi, S.: Forest productivity and water stress in Amazonia: observations from GOSAT chlorophyll fluorescence, Proc. Biol. Sci., 280, 20130 171, https://doi.org/10.1098/rspb.2013.0171, 2013.

Magney, T. S., Bowling, D. R., Logan, B. A., Grossmann, K., Stutz, J., Blanken, P. D., Burns, S. P., Cheng, R., Garcia, M. A., Köhler, P., Lopez, S., Parazoo, N. C., Raczka, B., Schimel, D., and Frankenberg, C.: Mechanistic evidence for tracking the seasonality of photosynthesis with solar-induced fluorescence, Proceedings of the National Academy of Sciences of the United States of America, 116, 11 640-11 645, https://doi.org/10.1073/pnas.1900278116, 2019.

Magney, T. S., Barnes, M. L., and Yang, X.: On the Covariation of Chlorophyll Fluorescence and Photosynthesis Across Scales, Geophysical Research Letters, 47, https://doi.org/10.1029/2020g1091098, 2020.

Maguire, A. J., Eitel, J. U. H., Griffin, K. L., Magney, T. S., Long, R. A., Vierling, L. A., Schmiege, S. C., Jennewein, J. S., Weygint, W. A., Boelman, N. T., and Bruner, S. G.: On the Functional Relationship Between Fluorescence and Photochemical Yields in Complex Evergreen Needleleaf Canopies, Geophysical Research Letters, 47, https://doi.org/10.1029/2020g1087858, 2020.

Marrs, J. K., Reblin, J. S., Logan, B. A., Allen, D. W., Reinmann, A. B., Bombard, D. M., Tabachnik, D., and Hutyra, L. R.: Solar-Induced Fluorescence Does Not Track Photosynthetic Carbon Assimilation Following Induced Stomatal Closure, Geophysical Research Letters, 47, https://doi.org/10.1029/2020g1087956, 2020.

Monteith, J. L.: Solar Radiation and Productivity in Tropical Ecosystems, Journal of Applied Ecology, 9, 747-766, 1972.

Parazoo, N. C., Bowman, K., Fisher, J. B., Frankenberg, C., Jones, D. B., Cescatti, A., Perez-Priego, O., Wohlfahrt, G., and Montagnani, L.: Terrestrial gross primary production inferred from satellite fluorescence and vegetation models, Global change biology, 20, 3103-21, https://doi.org/10.1111/gcb.12652, 2014.

Reichstein, M., Falge, E., Baldocchi, D., Papale, D., Aubinet, M., Berbigier, P., Bernhofer, C., Buchmann, N., Gilmanov, T., Granier, A., Grunwald, T., Havrankova, K., Ilvesniemi, H., Janous, D., Knohl, A., Laurila, T., Lohila, A., Loustau, D., Matteucci, G., Meyers, T., Miglietta, F., Ourcival, J.-M., Pumpanen, J., Rambal, S., Rotenberg, E., Sanz, M., Tenhunen, J., Seufert, G., Vaccari, F., Vesala, T., Yakir, D., and Valentini, R.: On the separation of net ecosystem exchange into assimilation and ecosystem respiration: review and improved algorithm, Global change biology, 11, 1424-1439, https://doi.org/10.1111/j.1365-2486.2005.001002.x, 2005.

Schaaf, C. B., Gao, F., Strahler, A. H., Lucht, W., Li, X., Tsang, T., Strugnell, N. C., Zhang, X., Jin, Y., Muller, J.-P., Lewis, P., Barnsley, M., Hobson, P., Disney, M., Roberts, G., Dunderdale, M., Doll, C., d'Entremont, R. P., Hu, B., Liang, S., Privette, J. L., and Roy, D.: First operational BRDF, albedo nadir reflectance products from MODIS, Remote Sensing of Environment, 83, 135-148, https://doi.org/10.1016/s0034-4257(02)00091-3, 2002.

Sellers, P. J.: Canopy reflectance, photosynthesis and transpiration, International Journal of Remote Sensing, 6, 1335-1372, https://doi.org/10.1080/01431168508948283, 1985.

Sims, D. A., Brzostek, E. R., Rahman, A. F., Dragoni, D., and Phillips, R. P.: An improved approach for remotely sensing water stress impacts on forest C uptake, Global change biology, 20, 2856-2866, https://doi.org/10.1111/gcb.12537, 2014. 
https://doi.org/10.5194/bg-2021-49

Preprint. Discussion started: 5 March 2021

(c) Author(s) 2021. CC BY 4.0 License.

(c) (i)

Smith, W. K., Dannenberg, M. P., Yan, D., Herrmann, S., Barnes, M. L., Barron-Gafford, G. A., Biederman, J. A., Ferrenberg, S., Fox, A. M., Hudson, A., Knowles, J. F., MacBean, N., Moore, D. J. P., Nagler, P. L., Reed, S. C., Rutherford, W. A., Scott, R. L., Wang, X., and Yang, J.: Remote sensing of dryland ecosystem structure and function: Progress, challenges, and opportunities, Remote Sensing of Environment, 233, 111 401, https://doi.org/10.1016/j.rse.2019.111401, 2019.

Sun, Y., Fu, R., Dickinson, R., Joiner, J., Frankenberg, C., Gu, L., Xia, Y., and Fernando, N.: Drought onset mechanisms revealed by satellite solar-induced chlorophyll fluorescence: Insights from two contrasting extreme events, Journal of Geophysical Research: Biogeosciences, 120, 2427-2440, https://doi.org/10.1002/2015jg003150, 2015.

Sun, Y., Frankenberg, C., Wood, J. D., Schimel, D. S., Jung, M., Guanter, L., Drewry, D. T., Verma, M., Porcar-Castell, A., Griffis, T. J., Gu, L., Magney, T. S., Kohler, P., Evans, B., and Yuen, K.: OCO-2 advances photosynthesis observation from space via solar-induced chlorophyll fluorescence, Science, 358, https://doi.org/10.1126/science.aam5747, 2017.

Sun, Y., Frankenberg, C., Jung, M., Joiner, J., Guanter, L., Köhler, P., and Magney, T.: Overview of Solar-Induced chlorophyll Fluorescence (SIF) from the Orbiting Carbon Observatory-2: Retrieval, cross-mission comparison, and global monitoring for GPP, Remote Sensing of Environment, 209, 808-823, https://doi.org/10.1016/j.rse.2018.02.016, 2018.

Turner, A. J. and Jacob, D. J.: Balancing aggregation and smoothing errors in inverse models, Atmos Chem Phys, 15, 7039-7048, https://doi.org/10.5194/acp-15-7039-2015, 2015.

Turner, A. J., Köhler, P., Magney, T. S., Frankenberg, C., Fung, I., and Cohen, R. C.: A double peak in the seasonality of California's photosynthesis as observed from space, Biogeosciences, 17, 405-422, https://doi.org/10.5194/bg-17-405-2020, 2020.

USDA: National Agricultural Statistics Service Cropland Data Layer: Published crop-specific data layer, https://nassgeodata.gmu.edu/ CropScape/, 2018.

Veefkind, J. P., Aben, I., McMullan, K., Förster, H., de Vries, J., Otter, G., Claas, J., Eskes, H. J., de Haan, J. F., Kleipool, Q., van Weele, M., Hasekamp, O., Hoogeveen, R., Landgraf, J., Snel, R., Tol, P., Ingmann, P., Voors, R., Kruizinga, B., Vink, R., Visser, H., and Levelt, P. F.: TROPOMI on the ESA Sentinel-5 Precursor: A GMES mission for global observations of the atmospheric composition for climate, air quality and ozone layer applications, Proc SPIE, 120, 70-83, https://doi.org/10.1016/j.rse.2011.09.027, 2012.

Wang, X., Dannenberg, M. P., Yan, D., Jones, M. O., Kimball, J. S., Moore, D. J. P., Leeuwen, W. J. D., Didan, K., and Smith, W. K.: Globally Consistent Patterns of Asynchrony in Vegetation Phenology Derived From Optical, Microwave, and Fluorescence Satellite Data, Journal of Geophysical Research: Biogeosciences, 125, https://doi.org/10.1029/2020jg005732, 2020.

Yang, H., Yang, X., Zhang, Y., Heskel, M. A., Lu, X., Munger, J. W., Sun, S., and Tang, J.: Chlorophyll fluorescence tracks seasonal variations of photosynthesis from leaf to canopy in a temperate forest, Global change biology, 23, 2874-2886, https://doi.org/10.1111/gcb.13590, 2017.

Yang, X., Tang, J., Mustard, J. F., Lee, J.-E., Rossini, M., Joiner, J., Munger, J. W., Kornfeld, A., and Richardson, A. D.: Solar-induced chlorophyll fluorescence that correlates with canopy photosynthesis on diurnal and seasonal scales in a temperate deciduous forest, Geophysical Research Letters, 42, 2977-2987, https://doi.org/10.1002/2015gl063201, 2015.

Yao, J., Liu, H., Huang, J., Gao, Z., Wang, G., Li, D., Yu, H., and Chen, X.: Accelerated dryland expansion regulates future variability in dryland gross primary production, Nature communications, 11, https://doi.org/10.1038/s41467-020-15515-2, 2020.

Yin, Y., Byrne, B., Liu, J., Wennberg, P. O., Davis, K. J., Magney, T., Köhler, P., He, L., Jeyaram, R., Humphrey, V., Gerken, T., Feng, S., Digangi, J. P., and Frankenberg, C.: Cropland Carbon Uptake Delayed and Reduced by 2019 Midwest Floods, AGU Advances, 1, https://doi.org/10.1029/2019av000140, 2020. 